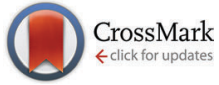

Cite this: Chem. Commun., 2015, 51, 9105

Received 19th February 2015, Accepted 24th April 2015

DOI: $10.1039 / \mathrm{c} 5 \mathrm{cc} 01536 \mathrm{~g}$

www.rsc.org/chemcomm

\section{A naphthalene diimide dyad for fluorescence switch-on detection of G-quadruplexes $\dagger$}

\author{
F. Doria, ${ }^{a}$ A. Oppi, ${ }^{a}$ F. Manoli, ${ }^{b}$ S. Botti, ${ }^{a}$ N. Kandoth, ${ }^{a}$ V. Grande, ${ }^{a}$ I. Manet* ${ }^{{ }^{b}}$ and \\ M. Freccero*a
}

\begin{abstract}
A non-fluorescent naphthalene diimide (NDI) dimer, conjugating red and blue NDI dyes, becomes red/NIR emitting upon G-quadruplex binding. The fluorescence lifetime which is significantly different for the complexes, the G-quadruplex/dimer and the weakly emitting ds-DNA/dimer is the key feature for the development of new rationally engineered G-quadruplex sensors.
\end{abstract}

Naphthalene diimides (NDIs) are a very versatile platform for the design of new molecular systems able to perform a variety of functions. ${ }^{1}$ Among various potential applications of NDIs, we have focused on core-substituted NDIs as selective nucleic acid (NA) ligands and fluorescent probes. Indeed, Neidle's group and our research unit have shown that tri- and tetra-substituted NDIs are potent and reversible ligands ${ }^{2-4}$ as well as alkylating agents targeting guanine rich NAs folded into G-quadruplex (G4) structures. ${ }^{5-8}$ G-rich sequences able to fold into G4 are present in oncogene promoters ${ }^{9-11}$ as well as human telomeres and participate in biological processes crucial for cell replication and survival. ${ }^{10,12}$ Consequently, they represent a very appealing target in the development of new therapeutic approaches based on their selective recognition by multimodal molecular tools. In this context, NDIs are particularly promising. In fact, apart from their G4 affinity, their optoelectronic properties can be effectively tuned by substituents on the aromatic core ${ }^{13-16}$ thus giving rise to absorption and emission in the red spectroscopic window which makes them appealing for fluorescence imaging and photodynamic therapy (PDT). ${ }^{17}$ In addition, the binding properties of NDIs toward G4s $\mathrm{s}^{3,6}$ may also be exploited for selective photocleavage as suggested for cationic Zn-phthalocyanines. ${ }^{18}$ Although fluorescence changes upon G4 binding has been extensively investigated using small molecule ligands, ${ }^{19}$ including guanidinium-modified phthalocyanines, ${ }^{20}$ effective $\mathrm{G} 4$ sensing by

\footnotetext{
${ }^{a}$ Dipartimento di Chimica, Università di Pavia, V. le Taramelli 10, 27100 Pavia, Italy. E-mail: mauro.freccero@unipv.it

${ }^{b}$ Istituto per la sintesi organica e la fotoreattività (ISOF), CNR, via Gobetti 101, 40129 Bologna, Italy. E-mail: ilse.manet@isof.cnr.it

$\dagger$ Electronic supplementary information (ESI) available. See DOI: 10.1039/c5cc01536g
}

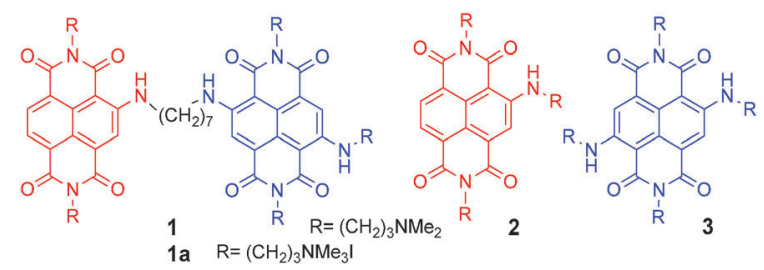

Scheme 1 Structure of dimeric NDI 1 (resulting from the merging of monomeric NDIs $\mathbf{2}$ and $\mathbf{3}$ ), and its quaternary ammonium salt $\mathbf{1 a}$, as iodide.

NDIs has seldom been attempted. ${ }^{21}$ A new strategy to engineer NDIs for G4 sensing was inspired by a series of monomeric NDIs with amine substituents on the naphthalene core having excellent water solubility, good fluorescence quantum yields as well as satisfactory quantum yields for singlet oxygen production upon excitation at $640 \mathrm{~nm} .{ }^{17}$ Here we report the synthesis and preliminary data of a water-soluble non-emitting dimeric NDI (1, Scheme 1) exhibiting a fluorescence turn-on response upon binding with specific DNA structures.

1 results from the conjugation of red tri-substituted dye 2 to blue tetra-substituted NDI 3, with a $\left(\mathrm{CH}_{2}\right)_{7}$ flexible spacer. Interestingly, time-resolved fluorescence measurements allowed differentiating between the G4 DNA complexes and ds DNA complexes of ligand 1. Dimer 1 was synthesised according to the protocol highlighted in Scheme 2. Exhaustive methylation of $\mathbf{1}$ gave the quaternary ammonium salt $\mathbf{1 a}$.

Imidation reaction of the commercially available 2,6-dibromo1,4,5,8-naphthalenetetracarboxylic dianhydride yielded quantitatively the 2,6-dibromo-substituted NDI 4, under acidic conditions. The subsequent nucleophilic aromatic substitution $\left(\mathrm{S}_{\mathrm{N}} \mathrm{Ar}\right)$ in the presence of an excess (2.5 eq.) of 1,7-diaminoheptane $\left(\mathrm{CH}_{3} \mathrm{CN}\right.$ as solvent, $75{ }^{\circ} \mathrm{C}, 4.5 \mathrm{~h}$ ) afforded a $60: 40$ mixture of NDIs 5 and 6 in a quantitative conversion. The lack of 5 vs. 6 selectivity was promptly solved by a reductive debromination step induced by $\mathrm{Na}_{2} \mathrm{~S}_{2} \mathrm{O}_{4}$ in aqueous acetonitrile $(1: 1)$, which converted 5 into 6 . The resulting crude was readily used for a second $\mathrm{S}_{\mathrm{N}} \mathrm{Ar}$ step on 4 , using a substoichiometric amount of 6 . The third microwave assisted $\mathrm{S}_{\mathrm{N}} \mathrm{Ar}$ was carried out by dissolving the resulting 7 in neat 


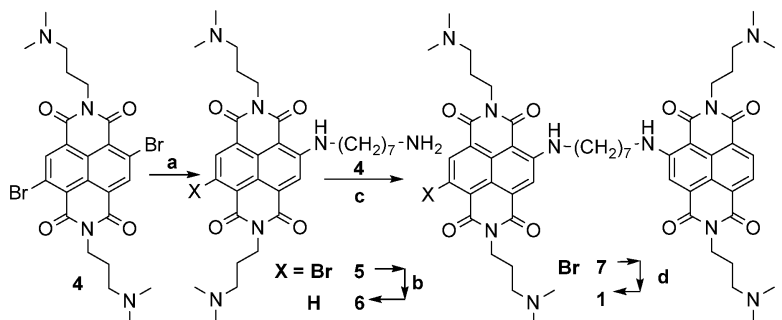

Scheme 2 Synthesis of the dimeric water soluble NDI 1. (a) 1,7-diaminoheptane 2.5 eq., $\mathrm{CH}_{3} \mathrm{CN}, 75^{\circ} \mathrm{C}, 4.5 \mathrm{~h}$; (b) $\mathrm{Na}_{2} \mathrm{~S}_{2} \mathrm{O}_{4} 2$ eq. in aqueous $\mathrm{CH}_{3} \mathrm{CN}$ (1:1), r.t. 1 h; (c) 0.95 eq. of $4, D M F, 50{ }^{\circ} \mathrm{C}, 5$ h; and (d) neat $N^{1}, N^{1}$-dimethylpropane-1,3-diamine, the microwave assisted protocol, and sealed reaction vessels (M.W.; $150{ }^{\circ} \mathrm{C}, 200$ psi, 250 bar, 200 W, 3 min).

$N^{1}, N^{1}$-dimethylpropane-1,3-diamine $\left(150{ }^{\circ} \mathrm{C}, 200 \mathrm{psi}, 250 \mathrm{bar}\right.$, $200 \mathrm{~W}, 3 \mathrm{~min}$, sealed reaction vessels) to give dimer 1 , which crystallised from the reaction mixture. The latter protocol systematically gave rise to almost quantitative yields. Filtration, further HPLC preparative purification $\left(\mathrm{CH}_{3} \mathrm{CN}: \mathrm{H}_{2} \mathrm{O}\right.$ and $0.1 \% \mathrm{CF}_{3} \mathrm{COOH}$ as eluent), and final anion exchange, yielded $\mathbf{1}$ as pentahydrochloride $(1 \times 5 \mathrm{HCl})$. The protonation mode of the solubilizing amino moieties controlling both the quenching of the excited states by electron transfer (eT) and NA binding was studied potentiometrically (Fig. 1a). The remarkable acidity of fully protonated 1 $\left(\mathbf{1 H}_{5}, \mathrm{p} K_{\mathrm{a}_{1}}=2.9\right)$ and the almost overlapping $\mathrm{p} K_{\mathrm{a}_{2}}$ and $\mathrm{p} K_{\mathrm{a}_{3}}(7.8$ and 7.9) suggest that $\mathbf{1}$ is mainly (90\%) tetra-cationic $\left(\mathbf{1 H}_{\mathbf{4}}\right)$ at $\mathrm{pH}$ 7. The monocationic $\left(\mathbf{1 H}_{\mathbf{1}}\right)$ and neutral forms are populated only under basic conditions $\mathrm{pH}>8\left(\mathrm{p} K_{\mathrm{a}_{4}} 8.75, \mathrm{p} K_{\mathrm{a}_{5}}\right.$ 9.12).

1 tends to aggregate at $\mathrm{pH}>7.8$ as inferred from the UV-vis absorption titrations (ESI, $\dagger$ Fig. S1). Nevertheless, the absorption spectra are almost superimposable at $\mathrm{pH} \leq 7$, so the protonation state of the $\mathrm{NMe}_{2}$ groups does not significantly affect the absorption spectra. The graphs in Fig. 1 show the
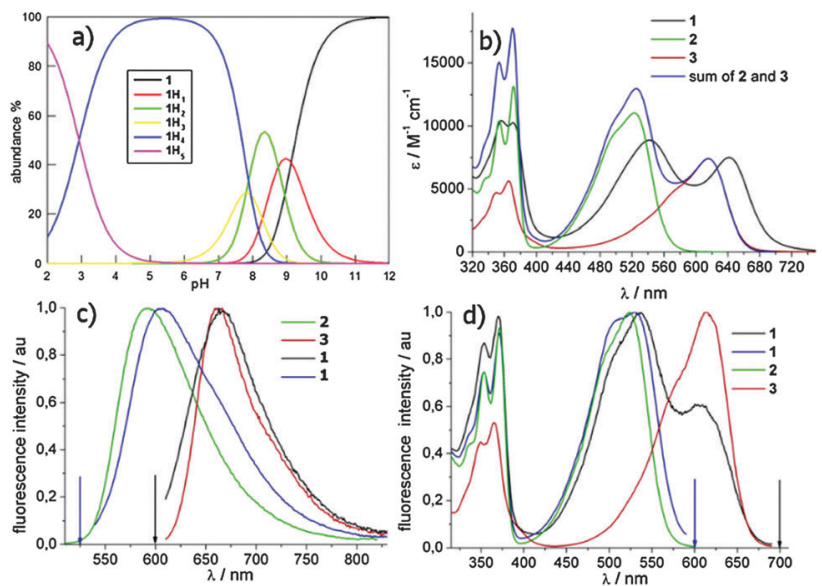

Fig. 1 (a) Speciation analysis describing the neutral, mono-, bi-, tri-, tetraand penta-cationic distribution of $\mathbf{1}\left(\mathbf{1}, \mathbf{1} \mathrm{H}_{1}, \mathbf{1} \mathrm{H}_{2}, \mathbf{1} \mathrm{H}_{3}, \mathbf{1} \mathrm{H}_{4}\right.$ and $\left.1 \mathrm{H}_{5}\right)$ resulting from the potentiometric titrations. (b) UV-vis absorption spectra of $1,2,3$ and the absorption sum spectrum of $2+3$; (c) normalized corrected fluorescence spectra of $\mathbf{1}$ and its monomeric analogues $\mathbf{2}$ and $\mathbf{3}$ obtained for different excitation wavelengths indicated by the arrows; (d) normalized corrected excitation spectra of 1, 2 and 3, measured at 600 and/or $700 \mathrm{~nm}$. Phosphate buffer (PB) of pH 2 . absorption (Fig. 1b), and corrected fluorescence spectra (Fig. 1c) as well as the fluorescence excitation spectra (Fig. 1d) of 1 in phosphate buffer at $\mathrm{pH}$ 2. Under these conditions, all of the aliphatic amines are fully protonated. The absorption band with vibronic signature in the $300-400 \mathrm{~nm}$ range is typical of the NDI core. ${ }^{22}$ The introduction of one or two amines is able to generate a second absorption band arising from a charge transfer (CT) transition involving the doublet of the aromatic amines. ${ }^{14,23}$ The absorption spectrum of $\mathbf{1}$ is clearly different from the sum of the spectra of the monomers (Fig. 1b) and displays red shifts for both absorption maxima ( $\left.\lambda_{\max } 542 / 642 \mathrm{~nm}\right)$. This bathochromic shift is quite remarkable $(26 \mathrm{~nm})$ for the longer wavelength maximum ( $\lambda_{\max } 642 \mathrm{~nm}$ ), which is exclusively due to the absorption of the tetra-substituted chromophore. The long and flexible spacer in the dimer likely allows strong interaction of the two aromatic cores in the ground state. Indeed, also the vibronic structure of the UV band changes markedly in dyad 1 . In the presence of SDS (sodium dodecyl sulphate) micelles, the two maxima of the visible band are similar to the monomer values indicating that ground state interaction has been disrupted (ESI, $\dagger$ Fig. S2). 1a has a superimposable absorption spectrum.

To rationalize the photophysical behavior of the most populated form of the dimer under physiological conditions $\left(\mathbf{1 H}_{\mathbf{4}}\right)$ we investigated some photophysical properties of the dimer and its monomeric homologues ( 2 and 3 ) in phosphate buffer of $\mathrm{pH} 7$ and 2 , where we observed the fully protonated one $\left(\mathbf{1 H}_{\mathbf{5}}\right)$.

Compared to NDI 3 the fluorescence quantum yield of $\mathbf{1}$, upon exclusive excitation at $600 \mathrm{~nm}$ of the tetra-substituted chromophore, is very low (Table 1). A pH increase from 2 to 7 causes a small reduction of the fluorescence quantum yield $\left(\Phi_{\mathrm{F}}\right.$, from 0.002 to 0.001 , ESI, $\dagger$ Fig. S3). $\Phi_{\mathrm{F}}$ does not change significantly passing to the quaternary ammonium salts $1 \mathbf{a}\left(\Phi_{\mathrm{F}}=\right.$ 0.003), suggesting a negligible effect of intramolecular electron transfer (eT) involving amine groups in the fluorescence quenching of both dyads $\mathbf{1}$ and 1a. The fluorescence lifetime $\left(\tau_{\mathrm{f}}\right)$ measured at $690 \mathrm{~nm}$ for $\mathbf{1}$, similar to the fluorescence lifetime of $4.2 \mathrm{~ns}$ obtained for $\mathbf{1 a}$, does not change with $\mathrm{pH}$, so probably we are observing static quenching in the dyad. Most likely, the interaction of the two chromophores, suggested above, accounts for additional non-radiative decay pathways of the excited states in the dyad. Evaluation of the fluorescence

Table 1 Photophysical properties of the NDI compounds 1, 2 and $\mathbf{3}$ in $0.01 \mathrm{M} \mathrm{K}^{+} \mathrm{PB}$ of $\mathrm{pH} 2$ or 7

\begin{tabular}{llllll}
\hline NDIs & $\begin{array}{l}\lambda_{\max } \\
(\mathrm{nm})\end{array}$ & $\begin{array}{l}\varepsilon_{\max } \\
\left(\mathrm{M}^{-1} \mathrm{~cm}^{-1}\right)\end{array}$ & $\Phi_{\mathrm{F}}{ }^{a}$ & $\begin{array}{l}\tau_{\mathrm{f}}^{b}(\mathrm{~ns}) \\
570 \mathrm{~nm}\end{array}$ & $\begin{array}{l}\tau_{\mathrm{f}}{ }^{c}(\mathrm{~ns}) \\
690 \mathrm{~nm}\end{array}$ \\
\hline 2@pH 2 & 522 & 11000 & $0.19^{d}$ & 5.60 & - \\
3@pH 2 & 616 & 7400 & $0.17^{d}$ & - & 4.40 \\
1@pH 2 & $542 / 642$ & $8870 / 7500$ & $0.002^{e}$ & $3.30,40 \%$ & 3.93 \\
& & & & $7.80,60 \%$ & \\
1@pH 7 & $542 / 642$ & $8870 / 7500$ & $0.001^{e}$ & $3.40,39 \%$ & 4.02 \\
& & & & $7.90,61 \%$ &
\end{tabular}

${ }^{a}$ Fluorescence quantum yields, see ref. 17 for 2 and $3 .{ }^{b}$ Fluorescence lifetime at $525 \mathrm{~nm}$ for excitation at $373 \mathrm{~nm} .{ }^{c}$ Fluorescence lifetime at $690 \mathrm{~nm}$ for excitation at $637 \mathrm{~nm} .{ }^{d}$ Fluorescence quantum yields of 0.15 and 0.13 have been reported in ref. 17 for compounds 2 and 3, respectively, at $\mathrm{pH}$ 7. ${ }^{e}$ Exciting at $600 \mathrm{~nm}$ and using monomer 3 as reference. 
quantum yields of the tri-substituted unit (emission peaking at $570 \mathrm{~nm}$ ) is not straightforward due to the overlapping absorption of the tetra unit inhibiting selective excitation of the former. The fluorescence intensity of the dyad for excitation at $525 \mathrm{~nm}$ in buffer of $\mathrm{pH} 2$ and $\mathrm{pH} 7$ is nearly identical (ESI, $\dagger$ Fig. S4). Further, upon changing $\mathrm{pH}$ the fluorescence lifetimes do not change for the tri unit. Taken all together these data suggest that the protonation state of the tri-substituted chromophore does not change from $\mathrm{pH} 2$ to 7 , while that of the tetraunit does. Therefore, the $\mathbf{1 H}_{\mathbf{4}}$ species has positive charges equally distributed on both units. The excitation spectra measured at $700 \mathrm{~nm}$ (Fig. 1d) give some additional information on the two interacting chromophores within the dyad. Even though we cannot exclude that the tri-substituted chromophore marginally contributes to the emission at $700 \mathrm{~nm}$ via direct emission, the profile of the excitation spectra gives strong evidence of energy transfer from the tri-substituted unit to the tetra one, which is feasible from the energetic point of view. This is also confirmed by the excitation spectra of the dimer in the presence of SDS (ESI, $\dagger$ Fig. S5). ${ }^{24}$ The two lifetimes measured at $570 \mathrm{~nm}$ may be due to the presence of dimers in different conformations one with a short lifetime $\left(\tau_{\mathrm{f}}=3.35 \pm 0.05 \mathrm{~ns}\right)$ and the other with a long lifetime $\left(\tau_{\mathrm{f}}=7.85 \pm 0.05 \mathrm{~ns}\right)$, with only the former favouring energy transfer.

The complexation behaviour of $\mathbf{1}$ towards four types of DNA has been studied using different spectroscopic techniques. In particular, we examined the interaction with ds DNA for the self-complementary strand $5^{\prime}$-[CAATCGGATCGAATTCGATCC GATTG]-3', with the hybrid and basket G4 of hTel22 as well as the parallel G4 of Pu22 as the model of the c-myc oncogene. The photophysical behaviour of the complexes strongly depends on the type of DNA. Binding has been studied titrating 1 with different amounts of DNA monitoring absorption, fluorescence and circular dichroism (CD) spectra as well as the fluorescence lifetimes. We refer to ESI $\dagger$ for absorption and circular dichroism data. CD spectra (ESI, $\dagger$ Fig. S7) show that 1 binds to parallel G4 of Pu22, basket G4 and ds DNA not disturbing the conformation. Differently in the case of Tel22, we conclude that binding favours transition from the G4 hybrid structure to other G4 structures. Global analysis of the multiwavelength data set corresponding to the fluorescence spectra of the different mixtures in Fig. 2 allowed us to determine the best complexation model, the binding constants of the most stable complexes (Table 2) as well as the individual fluorescence spectra of the associated species (ESI, $\dagger$ Fig. S9).

In the case of Pu22 the complexation model consists in the existence of two complexed species with $1: 1$ and $2: 1$ stoichiometry, only the $1: 1$ complex being fluorescent, while in the case of hTel22 with $\mathrm{K}^{+}$and $\mathrm{Na}^{+}$and ds26mer the analysis converged only with a complexation model of one fluorescent complex with $2: 1$ stoichiometry. Noticeably, we observed a 40-fold increase of the fluorescence quantum yield for the $1: 1$ complex of Pu22 and the $2: 1$ complex of htel 22 with $\mathrm{K}^{+}$compared to the isolated dimer (Table 2, ESI, $\dagger$ Fig. S9).

The selective turn-on effect upon complexation to G4 DNA by 1 (Fig. 3) is important from the point of view of possible
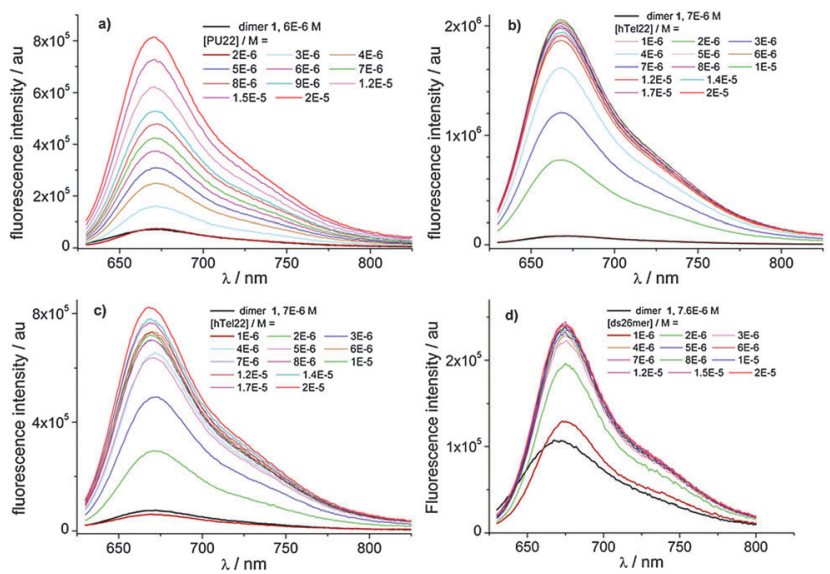

Fig. 2 Fluorescence spectra of $7.0 \times 10^{-6} \mathrm{M}$ solutions of 1 with increasing DNA concentration (range $1 \times 10^{-6}-2.0 \times 10^{-5} \mathrm{M}$ ) in phospate/ $\mathrm{KCl}$ or $\mathrm{NaCl}$ buffer, $\mathrm{pH}$ 7.0. The spectrum of dimer 1 solution is the black line. (a) Pu22 with $\mathrm{KCl}$; (b) hTel22 with KCl; (c) hTel22 with $\mathrm{NaCl}$; and (d) ds26mer.

Table 2 Stoichiometry and binding constants obtained from multiwavelength global analysis of the fluorescence titration data, together with the calculated fluorescence quantum yield of the indicated complex

\begin{tabular}{llll}
\hline DNA & $\begin{array}{l}\text { Stoichiometry } \\
\text { DNA : ligand }\end{array}$ & $\begin{array}{l}\mathrm{p} K_{11}\left(\mathrm{M}^{-1}\right) / \mathrm{p} K_{12}{ }^{a} \\
\left(\mathrm{M}^{-2}\right)\end{array}$ & $\Phi_{\mathrm{F}}{ }^{b}$ \\
\hline Pu22/KCl & $1: 1$ & 5.89 & 0.042 \\
& $1: 2$ & 12.66 & - \\
hTel22/KCl & $1: 2$ & 11.65 & 0.044 \\
hTel22/NaCl & $1: 2$ & 11.32 & 0.01 \\
ds26mer & $1: 2$ & 12.75 & 0.002
\end{tabular}

${ }^{a} K_{1 \mathrm{i}}$ binding constant, obtained using the commercially available program Reactlab Equilibria. ${ }^{b}$ Fluorescence quantum yield of the complex calculated using the spectra shown in ESI Fig. S9.

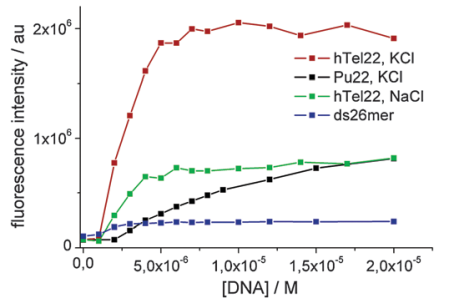

Fig. 3 Fluorescence intensity enhancement of a $7 \mu \mathrm{M}$ solution of 1 measured at $680 \mathrm{~nm}$ against DNA concentration. $\lambda_{\text {exc. }}=637 \mathrm{~nm}$.

applications of these molecules. 1a exhibits a less remarkable and selective turn-on emission upon binding, and for this reason, it has not been reported here (ESI, $\dagger$ Fig. S10).

Moreover, global analysis of the fluorescence decay data of $\mathbf{1}$ alone and in the presence of different concentrations of DNA obtained for excitation at $637 \mathrm{~nm}$ evidenced a different behaviour for the ds26mer NDI complexes. Only in the latter case, a tri-exponential function allowed convergence of global analysis while for G4 complexes a 4-exponential function was needed. In all fluorescent G4 complexes we observed a species with a long lifetime of $c a .5$ ns (ESI, $\uparrow$ Table S2) gaining importance with increasing DNA concentration, which is absent in the ds26mer 

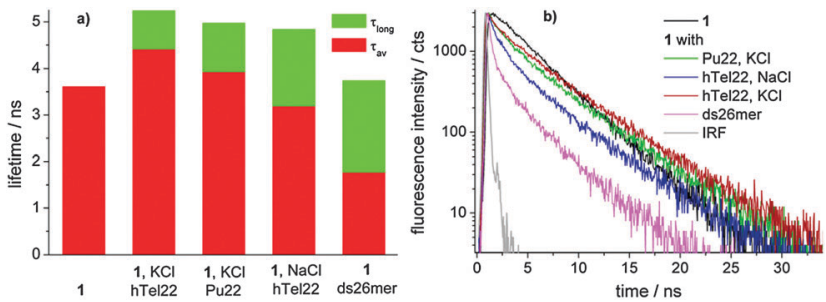

Fig. 4 (a) Graph displaying the long lifetime component ( $\tau_{\text {long, }}$ in green) as well as the average lifetime ( $\tau_{\mathrm{av}}$, in red) of solutions containing $7 \times 10^{-6} \mathrm{M} 1$ and $2 \times 10^{-5} \mathrm{M} \mathrm{DNA}$ in $0.01 \mathrm{M}$ phosphate buffer of $\mathrm{pH} 7.0$ with $100 \mathrm{mM} \mathrm{KCl}$ or $\mathrm{NaCl}$. (b) Fluorescence decay of compound $\mathbf{1}$ alone and in the presence of excess DNA.

complex (Fig. 4a). Fig. 4 also shows a graph with the average lifetime of a solution containing only NDI complexes.

The average lifetime $\left(\tau_{\text {av }}\right)$ of the ds DNA complex clearly differentiates from the average lifetime of the G4 complexes and this represents a very interesting tool to distinguish ds DNA NDI complexes from G4 NDI complexes. In all cases, the weak fluorescence ascribed to the tri-substituted NDI unit (red moiety in $\mathbf{1}$, Scheme 1) is completely quenched upon DNA complexation, paralleling the behaviour of NDI 2 upon hTel22 binding (ESI, $\dagger$ Fig. S11). Furthermore, the long fluorescence lifetime component of complex 1 obtained for excitation at $637 \mathrm{~nm}$ is similar to that of free $3(4.4 \mathrm{~ns})^{17}$ (Fig. 4). These data strongly suggest that the G4 binding moiety in dyad $\mathbf{1}$ is the tri-unit (red) and the flexible heptyl spacer allows the tetra-substituted (blue) moiety to assume a behaviour similar to that of free NDI 3. Indeed, the measured $\mathrm{p} K_{\mathrm{a}}$ values suggest that the protonation state of the two units has to be similar at $\mathrm{pH}$ 7. Electrostatic interactions of cationic G4 ligands with phosphate groups stabilizing the complexes are thus expected to be similar for both units. Other factors, such as steric hindrance and higher electron density on the aromatic core of the blue $v s$. red unit, may play a role in their different binding behaviour.

In conclusion, a water-soluble naphthalene diimide dyad conjugating red and blue NDIs was prepared and investigated as a fluorescent probe. The photophysical properties were thoroughly investigated by means of steady-state and timeresolved spectroscopy. Dyad $\mathbf{1}$ is a non-emitting molecule, unlike its NDI components. Upon complexation to G4 structures, the fluorescence of the dimer turns on in the red/NIR. Although the fluorescent probe does not exhibit remarkable selectivity between the investigated G4 structures, the G4 vs. ds selectivity is good. Furthermore, the average fluorescent lifetime of the G4 complexes with $\mathbf{1}$ is significantly different from the average fluorescent lifetimes of the ds complexes. This descriptor allows distinguishing the different types of complexes and it represents the most promising feature for the development of NDI dyads as fluorescent sensors for G4 structures by timeresolved fluorescence spectroscopy.
The Italian Ministry of Education, University and Research (MIUR), Rome (FIRB-Ideas RBID082ATK_003) and the Italian Association for Cancer Research (AIRC, IG2013-14708) financially supported this work.

\section{Notes and references}

1 S. V. Bhosale, C. H. Jani and S. J. Langford, Chem. Soc. Rev., 2008, $37,331$.

2 G. W. Collie, R. Promontorio, S. M. Hampel, M. Micco, S. Neidle and G. N. Parkinson, J. Am. Chem. Soc., 2012, 134, 2723.

3 F. Cuenca, O. Greciano, M. Gunaratnam, S. Haider, D. Munnur, R. Nanjunda, W. D. Wilson and S. Neidle, Bioorg. Med. Chem. Lett., 2008, 18, 1668.

4 M. Micco, G. W. Collie, A. G. Dale, S. A. Ohnmacht, I. Pazitna, M. Gunaratnam, A. P. Reszka and S. Neidle, J. Med. Chem., 2013, 56, 2959.

5 M. Di Antonio, F. Doria, S. N. Richter, C. Bertipaglia, M. Mella, C. Sissi, M. Palumbo and M. Freccero, J. Am. Chem. Soc., 2009, 131, 13132.

6 F. Doria, M. Nadai, M. Folini, M. Di Antonio, L. Germani, C. Percivalle, C. Sissi, N. Zaffaroni, S. Alcaro, A. Artese, S. N. Richter and M. Freccero, Org. Biomol. Chem., 2012, 10, 2798.

7 F. Doria, M. Nadai, M. Folini, M. Scalabrin, L. Germani, G. Sattin, M. Mella, M. Palumbo, N. Zaffaroni, D. Fabris, M. Freccero and S. N. Richter, Chem. - Eur. J., 2013, 19, 78.

8 M. Nadai, F. Doria, L. Germani, S. N. Richter and M. Freccero, Chem. - Eur. J., 2015, 21, 2330.

9 A. Siddiqui-Jain, C. L. Grand, D. J. Bearss and L. H. Hurley, Proc. Natl. Acad. Sci. U. S. A., 2002, 99, 11593.

10 (a) J. L. Huppert and S. Balasubramanian, Nucleic Acids Res., 2005, 33, 2908; (b) A. K. Todd, M. Johnston and S. Neidle, Nucleic Acids Res., 2005, 33, 2901.

11 J. L. Huppert and S. Balasubramanian, Nucleic Acids Res., 2007, 35, 406. 12 A. Rizzo, E. Salvati, M. Porru, C. D’Angelo, M. F. Stevens, M. D'Incalci, C. Leonetti, E. Gilson, G. Zupi and A. Biroccio, Nucleic Acids Res., 2009, 37, 5353.

13 (a) F. Doria, M. Folini, V. Grande, G. Cimino-Reale, N. Zaffaroni and M. Freccero, Org. Biomol. Chem., 2015, 13, 570; (b) F. Doria, C. M. Gallati and M. Freccero, Org. Biomol. Chem., 2013, 11, 7838.

14 C. Röger and F. Würthner, J. Org. Chem., 2007, 72, 8070.

15 F. Würthner, S. Ahmed, C. Thalacker and T. Debaerdemaeker, Chem. - Eur. J., 2002, 8, 4742.

16 N. Sakai, J. Mareda, E. Vauthey and S. Matile, Chem. Commun., 2010, 46, 4225.

17 F. Doria, I. Manet, V. Grande, S. Monti and M. Freccero, J. Org. Chem., 2013, 78, 8065.

18 K. W. Zheng, D. Zhang, L. X. Zhang, Y. H. Hao, X. Zhou and Z. Tan, J. Am. Chem. Soc., 2011, 133, 1475.

19 (a) A. Renaud de la Faverie, A. Guedin, A. Bedrat, L. A. Yatsunyk and J.-L. Mergny, Nucleic Acids Res., 2014, 42, e65; (b) P. Yang, A. De Cian, M.-P. Teulade-Fichou, J.-L. Mergny and D. Monchaud, Angew. Chem., Int. Ed., 2009, 48, 2188; (c) E. Largy, A. Granzhan, F. Hamon, D. Verga and M.-P. Teulade Fichou, Top. Curr. Chem., 2013, 330, 111.

20 (a) J. Alzeer, P. J. C. Roth and N. W. Luedtke, Chem. Commun., 2009, 1970; (b) A. Membrino, M. Paramasivam, S. Cogoi, J. Alzeer, N. W. Luedtke and L. E. Xodo, Chem. Commun., 2010, 46, 625.

21 F. Doria, M. Nadai, G. Sattin, L. Pasotti, S. N. Richter and M. Freccero, Org. Biomol. Chem., 2012, 10, 3830.

22 J. E. Rogers, S. J. Weiss and L. A. Kelly, J. Am. Chem. Soc., 2000, 122, 427. 23 S. Bhosale, A. L. Sisson, P. Talukdar, A. Furstenberg, N. Banerji, E. Vauthey, G. Bollot, J. Mareda, C. Roger, F. Wurthner, N. Sakai and S. Matile, Science, 2006, 313, 84.

24 Exciting 1 with SDS at $373 \mathrm{~nm}$ and measuring emission at $690 \mathrm{~nm}$ we observe a monoexponential decay indicating that only one species emits at $690 \mathrm{~nm}$, so in the presence of SDS the tri-unit does not contribute at this wavelength, ESI, $\dagger$ Fig. S6. 